Research paper

\title{
Recurrence rate and risk factors for recurrence of seizures after withdrawal of antiepileptic drugs (AED) in Indian children treated for epilepsy
}

\author{
Kavita Srivastava*, K.K. Kishore, Karan Topiwala, Surekha Rajadhyaksha \\ Bharati Vidyapeeth Medical College, Pune, India
}

\section{A R T I C L E I N F O}

\section{Article history:}

Received 1 July 2016

Accepted 5 December 2016

Available online 23 December 2016

\section{Keywords:}

AED withdrawal

Seizure recurrence

\section{Introduction}

Epilepsy is a major public health problem affecting about 50 million people worldwide. Even though it is a chronic condition, it may not remain life-long. The causes are variable and hence the outcome is also heterogeneous. ${ }^{1}$ There are considerable disadvantages of continuing AEDs indefinitely as they have potential adverse cognitive and behavioral side effects along with cost implications. $^{2}$

The decision to discontinue AED therapy is weighed against the chances of recurrence by the physicians. Previous studies in children have shown a risk of recurrence ranging from less than $10-70 \% .^{3-15} \mathrm{~A}$ few Indian studies have looked at risk factors of seizure recurrence in adults, ${ }^{16,17}$ but there is none such study in Indian children.

In India, the epidemiology of epilepsy is different from western countries in view of high burden of symptomatic epilepsy due to prevalence of birth asphyxia, neonatal hypoglycemia, etc. resulting from poor antenatal and natal care services. ${ }^{17}$ These children suffer from epilepsy of variable severity and the duration of treatment given is usually for 2-3 seizure free years after which the AED is/ are withdrawn. We did this study to evaluate the rate of recurrence in children after AED withdrawal and the associated risk factors and reviewed the literature for similar such studies.

\footnotetext{
* Corresponding author at: Bharati Vidyapeeth Medical College, Dhankawadi, Pune, India.

E-mail address: kavitasrivastava@yahoo.com (K. Srivastava).
}

\section{Methods}

Patients were selected from the Pediatric Epilepsy Clinic in a referral Medical College between July 2005 and December 2013. Out of 2200 patients referred for seizures, 1108 children were diagnosed with epilepsy. Children (below the age of 18 years) with unequivocal epilepsy, who had been treated for a seizure free period of 2-3 years, after which their anti-epileptic drugs (AED) were slowly tapered over 2-3 months were selected, who were followed up for a minimum period of 6 months. 148 such children were identified in whom recurrence and presence of risk factors was noted (Fig. 1).

\subsection{Inclusion criteria}

(1) Age below 18 years

(2) Children who had 2 or more unprovoked seizures

(3) Treated with anti-epileptic drugs (AED)

(4) Had been seizure free for 2-3 years

(5) Follow-up of minimum 6 months was available after withdrawal.

\subsection{Exclusion criteria}

(1) Children with single seizure but received AED

(2) Those with acute symptomatic seizures but received prolonged AED therapy

(3) Those on prolonged AED since neonatal period (after perinatal insult)

(4) Those diagnosed with inborn errors of metabolism

(5) Infants/Children with West syndrome.

The following factors were studied in these children: age of onset of seizures, sex, type of seizures, total duration of epilepsy, duration to control seizures after initiation of AED, number of AED used, number of seizures before starting AED, number of seizures after AED was started, total number of seizures, duration of AED therapy, age at withdrawal of AED, follow-up period after withdrawal, interval between AED withdrawal and seizure recurrence. To find the etiology, prior history of neonatal seizures, 


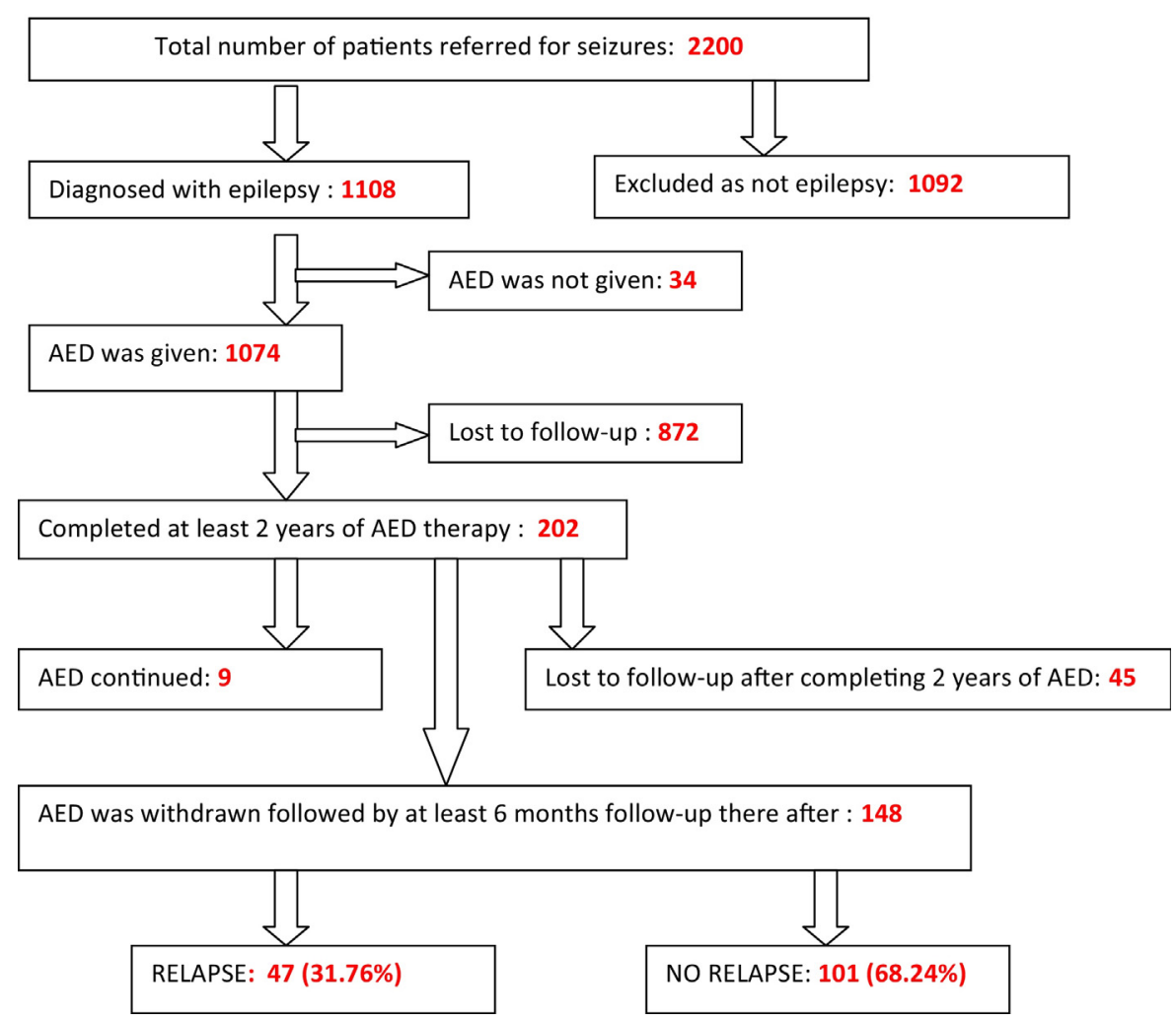

Fig. 1. Patient flowchart.

febrile seizures and family history of seizures was taken in detail. The motor and cognitive development and any morbidities were noted. Investigations included EEG at onset of AED, EEG before withdrawal, type of EEG abnormality and neuro-imaging findings (preferably MRI).

The data was entered on excel sheet. Those patients who did not follow up were called telephonically to check for seizure recurrence.

\subsection{Statistical analysis}

The information was collected and analyzed through SPSS (Statistical package for social sciences) version 17.0. For univariate analysis we have used Chi-square test, Fisher's exact test to find the association between recurrence and various risk factors. A multivariate analysis was carried out using Cox proportional Hazard model.
$P$ value $<0.05$ was significant,$<0.01$ - highly significant

A detailed review of literature was performed by entering the key words - AED withdrawal, recurrence, relapse, risk factors. Databases searched were Pubmed, Embase, various articles in journals related to epilepsy and neurosciences and their cross references.

\section{Results: background data: see Table 1}

\subsection{Rate and timing of recurrence}

Recurrence was seen in 47 cases, with a recurrence rate was $32 \%$. The time to recurrence varied from 1 month to 10 years (mean of 1.189 years) after withdrawal of AED. 68\% of total relapses occurred within 1 year, while $89 \%$ of relapses were within 2 years of withdrawal of AED. Thus only $11 \%$ relapse happened after 2 years of withdrawal (Fig. 2).

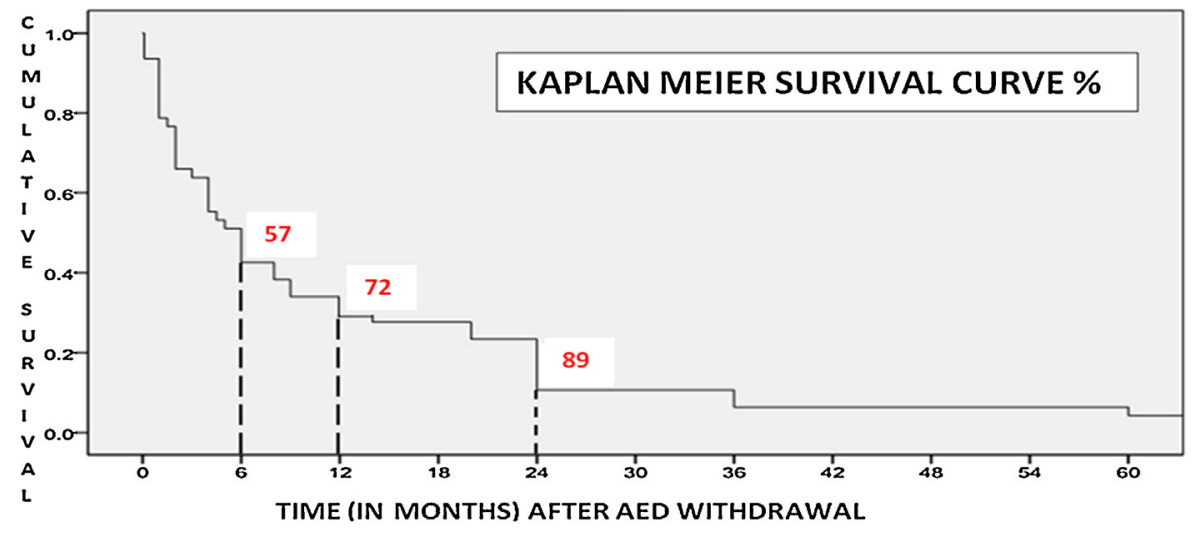

Fig. 2. Kaplan Meir curve for rate of recurrence. 
Table 1

Background data.

\begin{tabular}{|c|c|}
\hline Study parameter & Details \\
\hline Age (in years) & Range: $2.8-20$ years. Mean 4.34 years. \\
\hline Sex & Males: 96 (65\%), Females: 52 (35\%) \\
\hline Age of onset & Range: 2 months to 16 years. Mean: 4.99 years \\
\hline \multirow[t]{2}{*}{ Duration of active epilepsy (from 1st to last seizure) } & Less than 1 month (31), 2-6 months (33), 6 months to 1 year (24) \\
\hline & 1-3 years (29), 3-6 years (22), 7-10 years (9) Mean: 1.89 years \\
\hline Type of seizures & Focal/secondarily generalized: 94, generalized: 40, multiple types: 11 \\
\hline Focal epilepsy (111) & Carbamazepine (26) - 6 symptomatic focal, 20 cryptogenic: 10 recurred \\
\hline Total recurrence in 30 . & Phenytoin (8) - 2 symptomatic: 1 recurred \\
\hline \multirow[t]{4}{*}{ Details of drugs used: } & Phenobarbitone (10) - 2 symptomatic: 5 recurred \\
\hline & Valproate (26) - 11 symptomatic: 8 recurred \\
\hline & 2 drugs (14): 4 had recurrence, 3 drugs (8): 1 had recurrence \\
\hline & 4 and 5 drugs ( 1 each): 1 had recurrence \\
\hline \multirow[t]{2}{*}{ Generalized epilepsy (37) - recurrence in 13} & Valproate alone (16): 5 had recurrence \\
\hline & Valproate with other drugs (22): 8 had recurrence \\
\hline Number of AED used & Single (112), Two (23), Three (11), Four (1), Five (1) \\
\hline Seizures before start of AED & 2 (61), 3-5 (51), 6-10 (18), 10-20 (6), More than $20(12)$ \\
\hline Seizures after start of AED & $0(71), 1-2(26), 3-10(34), 10-20(11)$, More than $20(6)$ \\
\hline Total number of seizures & $2-5(82), 6-10(28), 10-20(18)$, More than $20(20)$ \\
\hline \multirow[t]{2}{*}{ Duration of AED therapy } & Range: $1.2-10$ years (Mean: 3.31 years). \\
\hline & 2 years ( 42$), 3$ years (25), $3-5$ years (32), 6-10 years (17). \\
\hline Etiology: & Idiopathic (14), Cryptogenic (77), Symptomatic (57) \\
\hline Duration of tapering & 3 months (122), 6 months (26) \\
\hline History of perinatal insult & $12(8.1 \%), 8$ had recurrence \\
\hline History of febrile seizures & $41(27 \%)$ \\
\hline \multirow[t]{2}{*}{ History of developmental delay } & 31 (20.9\%). 18 did not have cerebral palsy - 4 had recurrence. \\
\hline & 13 had cerebral palsy - out of which 8 had recurrence. \\
\hline Family history of seizures & $26(17.57 \%)$ \\
\hline EEG at onset (123) & $\begin{array}{l}\text { Normal (22) - } 8 \text { had recurrence, Focal discharges (63), multifocal discharges (21), } \\
\text { generalized spike/polyspike wave discharges (15) }\end{array}$ \\
\hline EEG at withdrawal (78) & Normal (45) - 9 had recurrence. Abnormal (33) - 9 had recurrence \\
\hline MRI findings (67) & Normal (42) - 12 had recurrence. Abnormal (25) - 13 had recurrence \\
\hline \multirow[t]{4}{*}{ Age at AED withdrawal } & 2.4 years to 19.6 years. \\
\hline & $2-3$ years $(10)-2$ had relapse, $3-5$ years $(32)-10$ had relapse \\
\hline & 5-7 years (26) - 11 had relapse, $7-10$ years $(28)-10$ had relapse \\
\hline & $10-15$ years (41) - 10 had relapse, More than 15 years $(11)-4$ had relapse \\
\hline \multirow[t]{3}{*}{ Follow up period (no. of patients) } & Range: 6 months to 13 years (Mean 2.06 years). \\
\hline & Follow up was available for 1 year (56), 1-2 years (43), 2-3 years ( 31 ), \\
\hline & $3-5$ years (12), 6-8 years (3), 10 (1) and $13(1)$ \\
\hline \multirow{5}{*}{$\begin{array}{l}\text { Timing of seizure recurrence on follow up } \\
\text { in } 47 \text { out of } 148 \text { patients }(\mathbf{3 1 . 7 6 \% )}\end{array}$} & Time to recurrence: 1 month to 10 years (Mean 1.189 years) \\
\hline & During withdrawal (7), Within 2 months (16), 3-6 months (11), \\
\hline & 6 months to 1 year (5), $1-2$ years (10), 3 years (2), 5 years (91), 10 years (2) \\
\hline & Total recurrence within 1 year of withdrawal: $32(68 \%)$ \\
\hline & Within 2 years: 89\%. After 2 years: $11 \%$ \\
\hline
\end{tabular}

\subsection{Risk factors for recurrence}

\subsubsection{Univariate analysis (Table 2)}

The following factors were found to be significantly associated with higher risk of recurrence - duration of active epilepsy (if more than 2 years), symptomatic etiology, prior history of neonatal seizures, concomitant cerebral palsy, response time after starting AED of more than 1 year, more than 2 seizures after start of AED therapy, total duration of AED given was more than 3 years.

The risk factors not found significant were gender, type of epilepsy, total number of seizures, past history of febrile seizures, family history of epilepsy, prior developmental delay alone (without associated cerebral palsy), EEG at onset of AED therapy as well as before withdrawal, abnormal neuro-imaging, number of AED required to control seizures, number of seizures before the start of AED, type of AED used, duration of AED withdrawal and age of AED withdrawal.

\subsubsection{Multivariate analysis: (Table 3)}

Cox proportional hazard model was used and three factors acquired significance for increased risk of seizures: duration of epilepsy more than 2 years, age of AED withdrawal if more than 10 years and total duration of AED more than 3 years.

\section{Discussion: comparison with other studies}

The literature search included adult and pediatric studies that looked at recurrence on follow up after AED withdrawal including a meta-analysis (Berg and Shinnar ${ }^{14}$ ) and a literature review $\left(\right.$ Britton $\left.^{15}\right)$.

Rate of recurrence: Most studies found a recurrence rate between $14 \%$ and $41 \%^{3-5,12-23,25-27}$ Patients with JME reported a higher relapse rate, up to $80 \%$ while only $6.2 \%$ in CAE. ${ }^{21}$ Ohta et al., ${ }^{12}$ reported a low recurrence rate of $9.2 \%$ in cryptogenic focal epilepsies with normal pre-withdrawal EEG. Hitiris et al., ${ }^{30}$ found 1 year seizure remission in upto $75 \%$ after treatment for 2-4 years. A prospective population based study (Cockerell et al., ${ }^{32}$ ) found 3 and 5 years remission in $86 \%$ and 54\% respectively, but they included single unprovoked seizures.

Timing of recurrence: In our study, $14 \%$ of relapses occurred during withdrawal, $68 \%$ within 1 year and $89 \%$ within 2 years of AED withdrawal. In other studies, $20-50 \%$ of relapses were noted during withdrawal itself. ${ }^{5,21,25}$ The percentage of relapses happening within 1 year of withdrawal ranged from (30$40 \%)^{5,13}$ in some studies to $(60-70 \%)^{14,16,19,21,23,27}$ up to more than $70 \%{ }^{25}$ The percentage of relapses that happened within 2 years of AED withdrawal were $(10-20 \%),{ }^{3,17}(20-30 \%),{ }^{20} 30-$ $40 \%,{ }^{4}(40-50 \%),{ }^{13}$ (70-80\%), ${ }^{3}$ and $95 \%{ }^{21}$ Thus, maximum 
Table 2

Univariate analysis: Relation of different risk factors to rate of recurrence.

\begin{tabular}{|c|c|c|c|c|c|c|c|}
\hline S.n. & Risk Factors & Categories & Numbers (\%) & Recurrence seen in & Relative risk & 95\% C.I. & $P$ value \\
\hline \multirow[t]{2}{*}{1.} & \multirow[t]{2}{*}{ Age of onset of epilepsy } & 1 year or less & $44(29.7)$ & $18(40.9)$ & \multirow[t]{2}{*}{1.467} & \multirow[t]{2}{*}{$0.916-2.349$} & \multirow[t]{2}{*}{0.127} \\
\hline & & More than 1 year & $104(70.2)$ & $29(27.8)$ & & & \\
\hline \multirow[t]{2}{*}{2.} & \multirow[t]{2}{*}{ Sex } & Male & $97(65.5)$ & $32(32.9)$ & \multirow[t]{2}{*}{1.123} & \multirow[t]{2}{*}{$0.672-1.869$} & \multirow[t]{2}{*}{0.713} \\
\hline & & Female & $51(34.5)$ & $15(29.4)$ & & & \\
\hline \multirow[t]{2}{*}{3.} & \multirow[t]{2}{*}{ Duration of active epilepsy } & 2 years or less & $106(71.6)$ & $25(23.5)$ & \multirow[t]{2}{*}{0.450} & \multirow[t]{2}{*}{$0.287-0.704$} & \multirow[t]{2}{*}{0.001} \\
\hline & & More than 2 years & $42(28.4)$ & $22(52.3)$ & & & \\
\hline \multirow[t]{2}{*}{4} & \multirow[t]{2}{*}{ Number of AED used } & One & $112(75.6)$ & $31(27.6)$ & \multirow[t]{2}{*}{0.623} & \multirow[t]{2}{*}{$0.338-0.998$} & \multirow[t]{2}{*}{0.067} \\
\hline & & More than 1 & $36(24.3)$ & $16(44.4)$ & & & \\
\hline \multirow[t]{2}{*}{5} & \multirow[t]{2}{*}{ Type of epilepsy } & Generalized & $38(25)$ & $13(35.1)$ & \multirow[t]{2}{*}{1.1} & \multirow[t]{2}{*}{$0.656-1.865$} & 0.706 \\
\hline & & Focal & $110(74.5)$ & $34(30.9)$ & & & \\
\hline 6 & Etiology & Idiopathic/cryptogenic & $91(61.5)$ & $20(21.9)$ & 0.464 & $0.288-0.7454$ & 0.001 \\
\hline & & Symptomatic & $57(38.5)$ & $27(47.3)$ & & & \\
\hline 7 & No. of seizures before starting AED & Two & $61(41.2)$ & $24(39.3)$ & 1.488 & $0.931-2.378$ & 0.097 \\
\hline & & More than two & $87(58.8)$ & $23(26.4)$ & & & \\
\hline 8 & No. of seizures after starting AED & $0-2$ & $97(65.5)$ & $25(25.7)$ & 0.597 & $0.376-0.948$ & 0.031 \\
\hline & & More than 2 & $51(34.5)$ & $22(43.1)$ & & & \\
\hline 9 & Time to control seizures & $0-12$ months & $108(73)$ & $3(2.7)$ & 0.05 & $0.016-0.159$ & $<0.001$ \\
\hline & & More than 12 months & $40(27)$ & $22(55)$ & & & \\
\hline 10 & Total duration of AED & 3 or less years & $99(66.8)$ & $20(20.2)$ & 0.367 & $0.230-0.584$ & $<0.001$ \\
\hline & & More than 3 years & $49(33.1)$ & $27(55.1)$ & & & \\
\hline 11 & $\mathrm{H} / \mathrm{o}$ seizures in neonatal period & Yes & $11(7.4)$ & $8(72.7)$ & 2.555 & $1.63-4.00$ & 0.005 \\
\hline & & No & $137(92.6)$ & $39(28.5)$ & & & \\
\hline 12 & Past h/o febrile seizures & Yes & $41(27.7)$ & $18(43.9)$ & 1.619 & $1.01-2.57$ & 0.075 \\
\hline & & No & $107(72.3)$ & $29(27.1)$ & & & \\
\hline 13 & Family h/o seizures & Yes & $26(17.5)$ & $5(19.2)$ & 0.559 & $0.244-1.274$ & 0.166 \\
\hline & & No & $122(82.4)$ & $42(34.4)$ & & & \\
\hline 14 & $\mathrm{H} / \mathrm{o}$ perinatal insult & Yes & $12(8.9)$ & $7(58.3)$ & 1.983 & $1.15-3.41$ & 0.053 \\
\hline & & No & $136(91.8)$ & $40(29.4)$ & & & \\
\hline 15 & H/o developmental delay & Yes & $31(21.1)$ & $12(38.7)$ & 1.283 & $0.76-2.16$ & 0.391 \\
\hline & & No & $116(78.9)$ & $35(30.2)$ & & & \\
\hline 16 & EEG at onset of AED (123 patients) & Normal & $22(17.2)$ & $8(38.1)$ & 0.598 & $0.311-1.148$ & 0.170 \\
\hline & & Abnormal & $101(82.7)$ & $33(22.7)$ & & & \\
\hline 17 & EEG at withdrawal of AED (78) & Normal & $45(57.7)$ & $9(20)$ & 1.364 & $0.604-3.057$ & 0.588 \\
\hline & & Abnormal & $33(42.3)$ & $9(27.2)$ & & & \\
\hline 18 & MRI findings (67 patients) & Normal & $42(62.3)$ & $12(28.6)$ & 1.820 & $0.999-3.345$ & 0.070 \\
\hline & & Abnormal & $25(37.3)$ & $13(52)$ & & & \\
\hline 19 & Concomitant cerebral palsy & Yes & $17(11.5)$ & $12(70.6)$ & 2.642 & $1.73-4.01$ & 0.001 \\
\hline & & No & $131(88.5)$ & $35(26.7)$ & & & \\
\hline 20 & Age of AED withdrawal & Less than 10 years & $104(70.2)$ & $35(33.6)$ & 1.23 & $0.709-2.14$ & 0.563 \\
\hline & & More than 10 years & $44(29.7)$ & $12(27.3)$ & & & \\
\hline 21 & Duration of AED withdrawal & 3 or less months & $122(82.4)$ & $37(30.3)$ & 0.789 & $0.452-1.374$ & 0.488 \\
\hline & & More than 3 months & $26(17.57)$ & $10(38.46)$ & & & \\
\hline
\end{tabular}

Table 3

Multivariate analysis for risk factors causing recurrence after AED withdrawal.

\begin{tabular}{|c|c|c|c|c|}
\hline \multirow[t]{2}{*}{ Risk factor } & \multirow[t]{2}{*}{$P$-value } & \multirow[t]{2}{*}{ Hazard ratio } & \multicolumn{2}{|c|}{ Confidence interval } \\
\hline & & & Lower & Upper \\
\hline Male sex & 0.253 & 0.451 & 0.115 & 1.768 \\
\hline Age of onset of seizures less than 1 year & 0.103 & 0.253 & 0.049 & 1.318 \\
\hline Duration of active epilepsy more than 2 years & 0.008 & 0.065 & 0.009 & 0.495 \\
\hline Time to control seizures more than 1 year & 0.930 & 1.102 & 0.127 & 9.591 \\
\hline More than 1 AED required to control seizures & 0.580 & 1.682 & 0.267 & 10.586 \\
\hline Symptomatic etiology & 0.724 & 0.595 & 0.033 & 10.641 \\
\hline More than 2 seizures before starting of AED therapy & 0.986 & 0.988 & 0.250 & 3.907 \\
\hline More than 2 seizures after starting AED therapy & 0.097 & 5.509 & 0.734 & 41.376 \\
\hline Previous history of febrile seizures & 0.388 & 1.798 & 0.475 & 6.809 \\
\hline Family history of epilepsy & 0.789 & 1.332 & 0.163 & 10.859 \\
\hline Prior history of perinatal insult & 0.306 & 0.293 & 0.028 & 3.074 \\
\hline History of delayed development & 0.186 & 0.228 & 0.026 & 2.037 \\
\hline Concomitant cerebral palsy & 0.222 & 3.298 & 0.485 & 22.430 \\
\hline Abnormal EEG at onset of AED & 0.804 & 0.604 & 0.011 & 32.752 \\
\hline Age of withdrawal of AED more than 10 years & 0.013 & 10.384 & 1.647 & 65.464 \\
\hline Total duration of AED more than 3 years & 0.036 & 0.101 & 0.012 & 0.860 \\
\hline History of seizures in neonatal period & 0.306 & 0.293 & 0.028 & 3.074 \\
\hline Abnormal EEG at withdrawal of AED & 0.241 & 2.381 & 0.559 & 10.150 \\
\hline Abnormal MRI & 0.753 & 0.647 & 0.043 & 9.705 \\
\hline Generalized epilepsy & 0.704 & 1.426 & 0.228 & 8.913 \\
\hline
\end{tabular}


Table 4

Risk factors for recurrence: comparison of our results with existing literature.

\begin{tabular}{|c|c|c|c|c|}
\hline Risk factor for recurrence & Our study result & $\begin{array}{l}\text { Studies that found the factor } \\
\text { significant }\end{array}$ & $\begin{array}{l}\text { Studies that } \\
\text { found the factor } \\
\text { not significant }\end{array}$ & $\begin{array}{l}\text { Comments on the basis of existing } \\
\text { literature }\end{array}$ \\
\hline Age of onset of epilepsy & $\begin{array}{l}\text { Not significant } \\
\text { (less or more } \\
\text { than } 1 \text { year) }\end{array}$ & $\begin{array}{l}\text { Older age of onset - more than } \\
10 \text { years } 8,14,15,17,21,26,31 \\
\text { More than } 5 \text { years }^{6} \\
\text { More than } 6 \text { years }^{12}\end{array}$ & $3-5,13,19,23$ & $\begin{array}{l}\text { Epilepsies with onset in adolescent } \\
\text { age may have more recurrence. }\end{array}$ \\
\hline Sex & Not significant & Female $^{3,7,21,22,33,40}$ & $4-6,13,17,19,23,27$ & $\begin{array}{l}\text { Female sex may act as additional } \\
\text { risk factor in IGE }\end{array}$ \\
\hline $\begin{array}{l}\text { Duration of active epilepsy more } \\
\text { than } 2 \text { years }\end{array}$ & Significant & $3,6,12,16,17,29,33,40$ & $30,23,27,34$ & $\begin{array}{l}\text { Surrogate marker for difficult to } \\
\text { control epilepsy }\end{array}$ \\
\hline Number of AED used more than one & Not significant & More than 1 drug $4,12,15,18,19,25-27$ & $3,5,6,16,17$ & $\begin{array}{l}\text { Surrogate marker for difficult to } \\
\text { control epilepsy }\end{array}$ \\
\hline Type of epilepsy - focal or generalized & Not significant & $\begin{array}{l}\text { Focal }^{4,13} \\
\text { Generalized } \\
\text { Multiple seizure types } \\
\text { 4,17,20,21 }\end{array}$ & $3,5,16,19,23,27$ & $\begin{array}{l}\text { Equivocal effect of type of seizures } \\
\text { but multiple seizure types confer } \\
\text { higher risk of recurrence }\end{array}$ \\
\hline Etiology - symptomatic versus idiopathic & Significant & $\begin{array}{l}\text { Remote } \\
\text { symptomatic }^{6,8,13-15,18,20,24,26,31,35-37,40} \\
\text { Idiopathic }^{2,14,15,17,21,26}\end{array}$ & $3,7,33$ & $\begin{array}{l}\text { Adolescent onset IGE may have } \\
\text { equal risk as Symptomatic }\end{array}$ \\
\hline More than 2 seizures before starting AED & Not significant & $12,17,34,44$ & $30,4,6,16,27,43$ & Equivocal \\
\hline More than 2 seizures after starting AED & Significant & $12,13,16,17,25,26,29,33,34$ & $30,6,27$ & $\begin{array}{l}\text { Surrogate marker for difficult to } \\
\text { control epilepsy }\end{array}$ \\
\hline $\begin{array}{l}\text { Time taken to control seizures was more } \\
\text { than } 1 \text { year after start of AED }\end{array}$ & Significant & Poor initial response $e^{3,6,12,13,15,38}$ & & $\begin{array}{l}\text { Surrogate marker for difficult to } \\
\text { control epilepsy }\end{array}$ \\
\hline Total duration of AED if more than 3 years & Significant & $\begin{array}{l}\text { Shorter duration } \\
\text { Prolonged } \text { AED }^{13,24,29,18,25,26,39}\end{array}$ & $5,16,17,19,41$ & Equivocal \\
\hline History of seizures in neonatal period & Significant & 17,20 & & Not studied adequately \\
\hline Past history of febrile seizures & Not significant & Febrile seizures ${ }^{4,20,27}$ & 3,6 & Not studied adequately \\
\hline Family history of seizures & Not significant & Positive family history ${ }^{15,17}$ & $3,5,16,27$ & $\begin{array}{l}\text { Family history of seizures may not } \\
\text { confer an additional risk for } \\
\text { recurrence }\end{array}$ \\
\hline $\begin{array}{l}\text { History of perinatal insult (asphyxia/ } \\
\text { hypoglycemia/seizures) }\end{array}$ & Significant & ( & 27 & Not studied adequately \\
\hline History of prior developmental delay & Not significant & Delayed development ${ }^{6,8,14,15,27,44}$ & $3,4,35$ & $\begin{array}{l}\text { Associated developmental delay has } \\
\text { higher risk of recurrence }\end{array}$ \\
\hline EEG at onset of AED (123 patients) & Not significant & Abnormal EEG $5,8,14,15,17,24,26,27$ & $3,4,6,7,23$ & $\begin{array}{l}\text { Abnormal EEG at onset of AED may } \\
\text { have a higher risk of recurrence }\end{array}$ \\
\hline EEG at withdrawal of AED (78) & Not significant & Abnormal EEG ${ }^{3-5,14,15,17,21,22,46}$ & 3 & $\begin{array}{l}\text { Abnormal EEG at withdrawal of AED } \\
\text { may have a higher risk of recurrence }\end{array}$ \\
\hline MRI findings (67 patients) & Not significant & Abnormal $^{17}$ & $3,23,27$ & Not adequately studied \\
\hline Concomitant cerebral palsy & Significant & $\begin{array}{l}\text { Motor deficits }{ }^{14,15,17,18,23} \\
\text { More risk in hemiplegia }^{45}\end{array}$ & 19 & $\begin{array}{l}\text { Associated Cerebral palsy has higher } \\
\text { risk of recurrence }\end{array}$ \\
\hline $\begin{array}{l}\text { Age of AED withdrawal more } \\
\text { than } 10 \text { years }\end{array}$ & Not significant & $12,21,22$ & $30,20,23,50$ & $\begin{array}{l}\text { Late onset epilepsies may have a } \\
\text { higher risk of recurrence. }\end{array}$ \\
\hline $\begin{array}{l}\text { Duration of AED withdrawal over } \\
3 \text { or more than } 3 \text { months }\end{array}$ & Not significant & Less than 3 months s $^{5,15,24}$ & $3,15,20,23,41,48,49$ & May not be significant \\
\hline
\end{tabular}

number of relapses is reported to occur within 2 years of withdrawal.

Risk factors for recurrence: Table 4 shows an overview of different risk factors found significant/not significant in our study and their status in the literature. We did not consider specific AEDs or post withdrawal EEG to look for worsening. History of neonatal seizures and perinatal insult (HIE, hypoglycemia) was not studied in most of the other existing literature.

Britton $^{15}$ asserted that abnormal EEG prior to withdrawal has limited predictive value, as some medications like Valproate may have EEG normalizing effects. They pointed out that relapse rates were up to $83 \%$ in patients whose EEG worsened on dose reduction, compared to $54 \%$ in patients whose EEG remained unchanged, suggesting that post withdrawal EEGs may be useful. Berg ${ }^{14}$ showed that slowing on EEG may be as important as presence of epileptiform abnormalities, as also photo-paroxysmal response which may be predict a higher risk of relapse.

\subsection{Multivariate analysis}

We found only three factors achieved significance-duration of epilepsy of more than 2 years, age at AED withdrawal if more than 10 years and duration of AED therapy if more than 3 years conferred a higher risk of recurrence. Different studies found various combinations of risk factors to be significant for recurrence: e.g. female sex, ${ }^{3,22}$ higher age of onset of seizures, ${ }^{12,25}$ time to control seizures more than 5 years, ${ }^{12}$ high initial seizure frequency, ${ }^{13}$ seizures after start of $\mathrm{AED},{ }^{25}$ remote symptomatic etiology, ${ }^{13}$ abnormal EEG at onset or withdrawal, ${ }^{22,25,27}$ abnormal neurological examination, ${ }^{23}$ generalized seizures (primary or secondary), ${ }^{25}$ polytherapy, ${ }^{27}$ etc.

Elson ${ }^{50}$ concluded that the most consistent factor is the ease of controlling seizures - how soon seizures are controlled on AED, frequency of seizures after AED initiation and the number of AED required to control seizures. Camfield and Camfield ${ }^{51}$ found the following factors to predict remission in children (Class I evidence): normal neurologic/mental abilities, seizure onset below the age of 12 years and infrequent or easily controlled seizures. The remission rate was $80 \%$ if all three factors were present versus $20 \%$ if none were present.

\subsection{Limitations of our study}

There were several limitations in our study. 22\% (45 out of 202) patients who completed 2 years of AED therapy did not follow up with us. Most patients were included retrospectively and the 
remaining patients were included over a period of 5 years from the onset of the study. Patients were treated for 2 or 3 years as per physician's discretion. It is possible that those patients who had difficult to control epilepsy and those who had florid abnormalities on pre withdrawal EEG were given prolonged therapy. We did not study type of EEG abnormalities, degree of mental retardation, etc. to stratify the risk of relapse. MRI was not available in many patients.

\section{Conclusion}

This is the first study to look at rate of recurrence and its risk factors amongst children treated for epilepsy in India. In general, older age of onset in a previously normal child points to Idiopathic generalized epilepsies (IGE) like JME which carry a greater risk of relapse even if easily controlled. Among the symptomatic group, mostly due to perinatal brain injury (asphyxia, hypoglycemia) the presence of co-morbidities like motor deficits, difficult to control seizures along with an abnormal EEG at withdrawal is associated with a higher rate of recurrence. There is no consensus in the world literature regarding the combination of prognostic factors to predict recurrence.

\section{Areas for further research}

Larger prospective studies with longer follow up to generate survival curves and to find out the factors affecting the rate of recurrence are needed to address this important issue with impact on future physical, economic and social well being of these children.

\section{Conflicts of interest}

The authors have none to declare.

\section{Acknowledgements}

We thank Mr. Shrivallabh Sane, Statistician, Department of Community Medicine, Bharati Vidyapeeth Medical College, Pune for assistance in statistical analysis.

\section{References}

1. Kale R. Global campaign against epilepsy: the treatment gap. Epilepsia. 2002 43(56):31.

2. Specchio LM, Beghi E. Should antiepileptic drugs be withdrawn in seizure-free patients? CNS Drugs. 2004;18(4):201-212

3. Olmez A, Arslan U, Turanli G, et al. Risk of recurrence after drug withdrawal in childhood epilepsy. Seizure. 2009;18:251-256.

4. Verriotti A, D’Egidio C, Agostinelli S, et al. Antiepileptic drug withdrawal in childhood epilepsy: what are the risk factors associated with seizure relapse. Arch Dis Child. 2011;96:113-115.

5. Magdy AA, Siam AG. Effect of the duration of withdrawal of antiepileptic drugs on the risk of seizure recurrence in childhood epilepsy. Egypt J Neurol Psychiat Neurosurg. 2010;47(4):593-598.

6. Bouma PAD, Peters ACB, Brouwer OF. Long term course of childhood epilepsy following relapse after antiepileptic withdrawal. J Neurol Neurosurg Psychiatry. 2002;72:507-510

7. Altunbasak S, Artar O, Burgut R, et al. Relapse risk analysis after drug withdrawal in epileptic children with uncomplicated seizures. Seizure. 1999:8:384-389.

8. Shinnar S, Berg AT, Moshe SL. Discontinuing antiepileptic drugs in children with epilepsy: a prospective study. Ann Neurol. 1994;35:534-545.

9. Pavlovic M, Jovic N, Pekmezovic T. Antiepileptic drugs withdrawal in patients with IGE. Seizure. 2011;20(September (7)):520-525.

10. Andersson T, Braathen G, Persson A, et al. A comparison between one and three years of treatment in uncomplicated childhood epilepsy: a prospective study. Il. The EEG as predictor of outcome after withdrawal of treatment. Epilepsia. 1997; 38(2):225-232.

11. Caviedes BE, Herranz JL. Seizure recurrence and risk factors after withdrawal of chronic antiepileptic therapy in children. Seizure. 1998;7(2):107-114.

12. Ohta H, Ohtsuka Y, Tsuda T, et al. Prognosis after withdrawal of antiepileptic drugs in childhood-onset cryptogenic localisation related epilepsies. Brain Dev. 2004 26(1):19-25.
13. Sillanpaa M, Schmidt D. Prognosis of seizure recurrence after stopping antiepileptic drugs in seizure free patients: a long term population based study of childhood onset epilepsy. Epilepsy Behav. 2006;8:713-719.

14. Berg AT, Shinnar S. Relapse following discontinuation of antiepileptic drugs: a meta-analysis. Neurology. 1994;44:601-608.

15. Britton J. Antiepileptic drug withdrawal: literature review. Mayo Clin Proc. 2002;77:1378-1388

16. Verma A, Mishra S. Risk of seizure recurrence after antiepileptic withdrawal, an Indian study. Neurol Asia. 2006;11:19-23.

17. Lamdhade SJ, Taori GM. Study of factors responsible for recurrence of seizures in controlled epileptics for more than 1.5 years after withdrawal of antiepileptic drugs. Neurol India. 2002;50:295-300.

18. Medical Research Council Antiepileptic Drug Withdrawal Study Group.Randomised study of antiepileptic drug withdrawal in patients in remission. Lancet. 1991;337:1175-1180.

19. Boonluksiri P. Risk of seizure recurrence after antiepileptic drug withdrawal in Thai children with epilepsy. Neurol Asia. 2006;11:25-29.

20. Ramos-Lizana J, Aguirre-Rodriguez J, Aguilera-Lopez P, et al. Recurrence risk after withdrawal of antiepileptic drugs in children with epilepsy: a prospective study. Eur J Pediatr Neurol. 2010;14(2):116-124.

21. Pavlovic M, Jovic N, Pekmezovic T. Antiepileptic drugs withdrawal in patients with idiopathic generalized epilepsy. Seizure. 2011;20(7):520-525.

22. Pavlovic M, Jovic N, Pekmezovic T. Withdrawal of antiepileptic drugs in young patients with cryptogenic focal epilepsies. Seizure. 2012;21(6):431-436.

23. Lossius MI, Hessen E, Mowinckel P, et al. Consequences of antiepileptic drug withdrawal: a randomized Double Blind Study (Akhershus Study). Epilepsia. 2008:49:455-463.

24. Hawash KY, Rosman NP. Do partial seizures predict an increased risk of seizure recurrence after antiepilepsy drugs are withdrawn? J Child Neurol. 2003;18(5): 331-337.

25. Prognostic index for recurrence of seizures after remission of epilepsy. Medical Research Council Antiepileptic Drug Withdrawal Study Group. BMJ. 1993;306: 1374-1378.

26. Bonnett LJ, Shukralla A, Tudur-Smith C. Seizure recurrence after antiepileptic drug withdrawal and the implications for driving: further results from the MRC Antiepileptic Drug Withdrawal Study and a systematic review. J Neurol Neurosurg Psychiatry. 2011;82:1328-1333.

27. Incecik F, Herguner OM, Altunbasak S, et al. Risk of recurrence after discontinuation of antiepileptic drug therapy in children with epilepsy. J Pediatr Neurosci. 2014;9(2):100-105.

29. Speechio LM, Tramacere L, La Neve A, et al. Discontinuing antiepileptic drugs in patients who are seizure free on monotherapy. J Neurol Neurosurg Psychiatry. 2002;72(1):22-25.

30. Hitiris N, Mohanraj R, Norrie J, et al. Predictors of pharmaco-resistant epilepsy. Epilepsy Res. 2007;75:192-196.

31. Peters AC, Brouwer OF, Geerts AT, et al. Randomized prospective study of early discontinuation of antiepileptic drugs in children with epilepsy. Neurology. 1998:50:724-730.

32. Cockerell OC, Johnson AL, Sander JW, et al. Prognosis of epilepsy: a review and further analysis of the first nine years of British national General practice. Study of epilepsy: a prospective population based study. Epilepsia. 1997;38:31-46.

33. Dooley J, Gordon K, Camfield P, et al. Discontinuation of anticonvulsant therapy in children free of seizures for 1 year: a prospective study. Neurology. 1996;46: 969-974.

34. Mohanraj R, Brodie MJ. Diagnosing refractory epilepsy: response to sequential treatment schedules. Eur J Neurol. 2006;13:277-282.

35. Tinuper P, Avoni P, Riva R, et al. The prognostic value of the electroencephalogram in antiepileptic drug withdrawal in partial epilepsies. Neurology. 1996:47:76-78.

36. Avoni P, Riva R, Tinuper P. Prognosis of epilepsies in antiepileptic drugs discontinuation. Epilepsia. 1996;37(suppl 4):58-59.

37. Braathen G, Melander H. Early discontinuation of treatment in children with uncomplicated epilepsy: a prospective study with a model for prediction of outcome. Epilepsia. 1997;38:561-569.

38. Sillanpaa M, Jalava M, Kaleva O, et al. Long term prognosis of seizures with onset in childhood. N Engl J Med. 1998;338:1715-1722.

39. Berg AT, Shinnar S, Levy SR, et al. Two year remission and subsequent relapse in children with newly diagnosed epilepsy. Epilepsia. 2001;42:1253-1262.

40. Hixson JD. Stopping antiepileptic drugs: when and why. Curr Treat Options Neurol. 2010:12:434-442.

41. Tennison M, Greenwood R, Lewis D, et al. Discontinuing antiepileptic drugs in children with epilepsy: a comparison of a 6 week and a 9 month taper period. $N$ Engl J Med. 1994;330:1407-1410.

42. Sirven JL, Sperling M, Wingerchuk DM. Early versus late antiepileptic drug withdrawal for people with epilepsy in remission. Cochrane Database Syst Rev. 2002;(3).

43. MacDonald BK, Johnson AL, Goodridge DM, et al. Factors predicting prognosis of epilepsy after presentation with seizures. Ann Neurol. 2000;48:833-841.

44. Arts WF, Brouwer OF, Peters AC, et al. Course and prognosis of childhood epilepsy: 5 year follow-up of the Dutch study of epilepsy in childhood. Brain. 2004; 127:1774-1784

45. Delgado MR, Riela AR, Mills J, et al. Discontinuation of antiepileptic drug treatment after two seizure free years in children with cerebral palsy. Pediatrics. 1996; 97:192-197.

46. Andersson T, Brathen G, Persson A, et al. A comparison between one and three years of treatment in uncomplicated childhood epilepsy: a prospective study, II: the EEG as predictor of outcome after withdrawal of treatment. Epilepsia. 1997; $38: 225-232$ 
47. Serra J, Montenegro M, Guerreiro M. Antiepileptic drug withdrawal in childhood: does the duration of tapering off matter for seizure recurrence? J Child Neurol. 2005;20(7):624-626.

48. Guerra S, Augusta M, Guerreiro M. Antiepileptic drug withdrawal in childhood. Does the duration of tapering off matter for seizure recurrence? J Child Neurol. 2005;20(7):624-626.
49. Ranganathan LN, Ramaratnam S. Rapid versus slow withdrawal of antiepileptic drugs. Cochrane Database Syst Rev. 2006;(2):CD005003.

50. Elson L. Predictors of outcome in newly diagnosed epilepsy: clinical, EEG and MRI. Neurol Asia. 2011;16(1):27-29.

51. Camfield PR, Camfield CS. Childhood epilepsy: what is the evidence for what we think and what we do. J Child Neurol. 2003;18:272-287. 